\title{
Impact on Vector-Borne Diseases in COVID-19 Pandemic: Evidence from a District in Jharkhand, India
}

\author{
Vidushi Topno $^{1}$, Vikas Oraon ${ }^{2}$ \\ ${ }^{1}$ Tutor, Department of Microbiology, Phulo Jhano Medical College, Dumka. \\ ${ }^{2}$ Assistant Professor, Department of Microbiology, Phulo Jhano Medical College, Dumka
}

Corresponding Author: Vidushi Topno

\begin{abstract}
The study is aimed to assess the effect of COVID-19 pandemic and non-pharmaceutical interventions (NPI) like banning mass gatherings (Lockdown) etc on vector borne diseases. This study can throw some light on the epidemiology of all vector-borne diseases under surveillance during this COVID-19 pandemic. This study is done in Dumka district, Jharkhand. Method- A cross-sectional study was conducted in 10 Blocks of Dumka District. Sampling technique used in this study was convenience sampling. Study of six month was conducted for vector-borne diseases from January 2021- June 2021.To know the epidemiology of vector-borne disease before and after COVID-19 pandemic, data from the year 2019 and 2020 was used for data analysis.

Result - During the six months study period between January 2021-June 2021, maximum number of cases found in Dumka District was Kala-azar followed by Lymphatic Filariasis and then Malaria. There was sharp decrease in number of vector-borne disease cases. After data analysis between the year 2019 and 2020 reduction of cases was seen in Kala-azar (15.3\%), Lymphatic Filariasis (8.9\%) and maximum reduction of cases was seen Malaria (98.1\%).

Conclusion - A drastic reduction in reported cases of vector-borne diseases was noticed. To better understand the reason behind the changes in vector-borne disease prevalence a consistent and vigilant surveillance is required.
\end{abstract}

Keywords: COVID-19, Vector-borne diseases, non-pharmaceutical interventions

\section{INTRODUCTION}

The COVID-19 pandemic has affected almost all countries and territories and was a global outbreak. In Wuhan, China this outbreak was first recognised in December 2019.The public all around the world was cautioned to take amenable care. Physical distancing, face mask wearing, hand washing and avoidance of mass gathering were the public protection strategies. To control the transmission of COVID-19 pandemic, lockdown and staying home strategies were the much needed actions. ${ }^{1}$

The important vector-borne diseases of India are Malaria, Dengue, Japanese Encephalitis, Kala-azar, Lymphatic Filariasis and Chikungunya. ${ }^{2}$ Globally, 67\% of Visceral Leishmaniasis (Kala-azar) are found in India, Nepal and Bangladesh. ${ }^{3}$ Since 2012, process of eradication of disease is in progress in India but still it is stable in four middle-eastern states. Jharkhand is also one of the endemic state for kala-azar. Jharkhand state during the period from 2000 to 2011 had 44,180 reported cases. $^{4} \mathrm{VL}$ is still an obstacle to socio-economic development in India and continues to constitute immense public health problems.

Malaria is also a major health problem. It is a mosquito-borne disease caused by Plasmodium group and commonly spread by Anopheles mosquito bite. In tropical areas malaria is widespread 
including Africa, Asia and Latin America. As observed, 61\% cases in SEAR countries are from India with $41 \%$ malaria deaths. ${ }^{5}$ In India about 1.0 million malaria cases were reported in 2014. ${ }^{6}$ During this COVID-19 pandemic World Health Organisation (WHO) has emphasised crucial need to endure efforts to prevent, detect and treat malaria during this pandemic.

Most common vector-borne disease after malaria is human Lymphatic filariasis (LF). It is a disease caused by roundworm nematode which is a parasite of helminthiases group. ${ }^{8}$ It is most commonly prevalent globally and is a Neglected tropical disease (NTD). ${ }^{9} \quad$ Lymphatic Filariasis also called as 'elephantiasis' mainly affects legs and genitals. Hydrocele in males and breast filariasis in female which causes persistent disability causing social stigma. The parasite causes damage to the lymphatic system leading to body organs deformity. As estimated by WHO LF is found in 81 tropical and subtropical countries. Globally, it was estimated that there were 120 million infected cases with one billion people at risk. About $70 \%$ of the LF infection in the world is contributed by four countries India, Indonesia, Bangladesh and Nigeria. ${ }^{10}$

Immense pressure is placed by COVID-19 pandemic on health systems worldwide. This is especially evident in resource-poor settings with limited range to treat and hold new disease outbreaks. ${ }^{11}$

First reported case of COVID-19 infection was from Kerala in India, on January 27, 2020. ${ }^{12}$ Announcement of Lockdown on 23 March in Kerela and on 25 March in rest of the country India. ${ }^{12}$ This study to see the impact of COVID-19 on vector-borne diseases is conducted in Dumka District which is the sub-capital of Jharkhand state, India. Most common vector-borne diseases encountered here are Kala-azar, Malaria and Lymphatic Filariasis. Other vector-borne diseases like Dengue, Japanese encephalitis and Chikungunya are rarely confronted in this area. Due to global outbreak of Covid-19 pandemic several strategies have been applied against this pandemic. Strategies like lockdown and staying at home were conducted. The objective of this study is to observe any effect of these strategies in prevalence of vector borne diseases. In a study conducted it was observed that the public health interventions initiated to halt the COVID-19 spread have affected vector borne disease outcome. ${ }^{13,14}$ Present study aims to assess the overall effect of COVID19 in vector-borne diseases in District Dumka, Jharkhand.

\section{MATERIALS AND METHODS}

This was a community based CrossSectional study conducted among the population belonging to Dumka District. The study was accomplished in Phulo Jhano Medical College, Dumka in Department of Microbiology, between January 2021 to June 2021. Since first cases of COVID-19 in India were reported in January 2020 and lockdown in March 2020, a study is among done among the number of vector-borne disease cases in the year 2019 and 2020.This will show the prevalence of disease before and after the COVID-19 pandemic.

\section{Sample size and sampling technique}

Data was analysed from the line-list of the District Vector Borne Disease Control Office (DVBDCO), Dumka, during (January 2021 - June 2021) along with number of cases in year end of 2019 and 2020 (one year duration). There are 10 Blocks in Dumka District which were included in this study (Dumka Sadar, Jama, Shikaripara, Ranishwer, Masalia, Kathikund, Gopikander, Ramgarh, Jarmundi and Saraiyahat).

The sampling technique used in this study was convenience sampling. Inclusion criteria of cases consisted of all cases of vector- borne diseases of Dumka District only. Vector-borne diseases belonging to Districts other than Dumka were excluded. To assess the situation of disease in Dumka District various variables were used like 
age, sex, weight, date of onset of symptoms, date of diagnosis, treatment history, date of completion of treatment. All the statistical analysis and graph preparations were performed using Excel and SPSS 20.0. Both parametric and non-parametric tests were applied determined by data.

\section{RESULT}

The study includes all vector-borne diseases that have been reported in District Dumka. Number of cases seemed to decrease in almost all vector-borne disease recorded in this area. There is decline in number of cases of kala-azar, Malaria, Lymphatic Filariasis cases when the recorded cases of 2020 (1year) were compared with 1 year record of 2019. It was only PKDL (Post Kala-azar Dermal Leishmaniasis) which showed increase in 2020. Maximum number of cases encountered here was Kala-azar. Highest number of cases seen in 2019 was Kala-azar , followed by Malaria and Lymphatic Filariasis while in 2020 there was sharp decline in number of malaria cases, so the highest number of cases seen were Kalaazar, followed by Lymphatic Filariasis and then Malaria cases.

\section{Kala-azar and PKDL (Post Kala-azar Dermal Leishmaniasis)}

In the present year 2021, recorded cases of Kala-azar from month of January to June were 47 cases and 13 cases of PKDL were recorded. Male patients were 68.6\% while females were $31.4 \%$. There were $19.1 \%$ cases of children below 14 years and above 14 years were $80.8 \%$. Among PKDL cases $61.5 \%$ cases were males while $38.5 \%$ cases were female. There were $7.7 \%$ cases of PKDL below the age of 14 years and $92.3 \%$ cases above the age of 14 years. So, male cases were predominant in both Kalaazar and PKDL during six months duration. Kala-azar was the main presentation followed by PKDL. Maximum number of Kala-azar cases were recorded from Dumka Sadar (29.8\%) followed by Jama (25.5\%). In PKDL maximum number of cases were recorded from Ramgarh (30.8\%) followed by Dumka Sadar (23.1\%). Before the entrance of COVID-19 pandemic in India, one year record in 2019 year end was 157 cases of Kala-azar and 25 cases of PKDL. After the arrival of COVID-19 in India, one year record in 2020 year end was 133 cases of Kala-azar and 41 cases of PKDL. There was $15.3 \%$ reduction in Kala-azar cases and $64 \%$ rise in PKDL cases in 2020 when compared with the year 2019.The total endemicity of Dumka District for Kala-azar in January 2021 to June 2021 was 0.28.

\section{Lymphatic Filariasis}

After Kala-azar cases, most common vector-borne disease analysed from data was Lymphatic Filariasis. During the 6 months study period in 2021 from January to June the number of cases were 38. Male cases were $72.7 \%$ while females were 27.3\% cases. Age group maximum affected were between $31-50$ years (59.2\%) and cases below 14 years were (7.4\%). Lymphatic Filariasis was predominantly found in males. Leg was the main organ affected (52.6\%) followed by scrotum (44.7\%) then hand (2.6\%). In the year 2019, total 67 cases were detected which reduced to 61 cases in 2020. There was case reduction of $8.9 \%$. So, reduction of cases was seen even in Lymphatic Filariasis. Maximum cases were recorded from Block Saraiahat (42.1\%) followed by Shikaripara (21.1\%) then Dumka Sadar (18.4\%).

\section{Malaria}

Vector borne disease found after Lymphatic Filariasis in Dumka District is Malaria. In year 2019 this disease was recorded as second highest after Kala-azar. In 2019 there were 103 cases which reduced to only 2 cases in the year end of 2020.The case reduced to $98.1 \%$. A surveillance is required to assess the cause for this sharp decrease in recorded cases of malaria. In this 6 months study period between January 2021 to June 2021 only 2 cases of malaria were recorded from Block Kathikund. Due 
Vidushi Topno et.al. Impact on vector-borne diseases in COVID-19 pandemic: evidence from a district in Jharkhand, India.

to limited data, we were unable to do further analysis about Malaria disease cases.

\section{Other Vector-Borne disease}

Till now there were no recorded case of Dengue, Chikungunya and Japanese Encephalitis. Thus, data analysis was not done with these diseases.

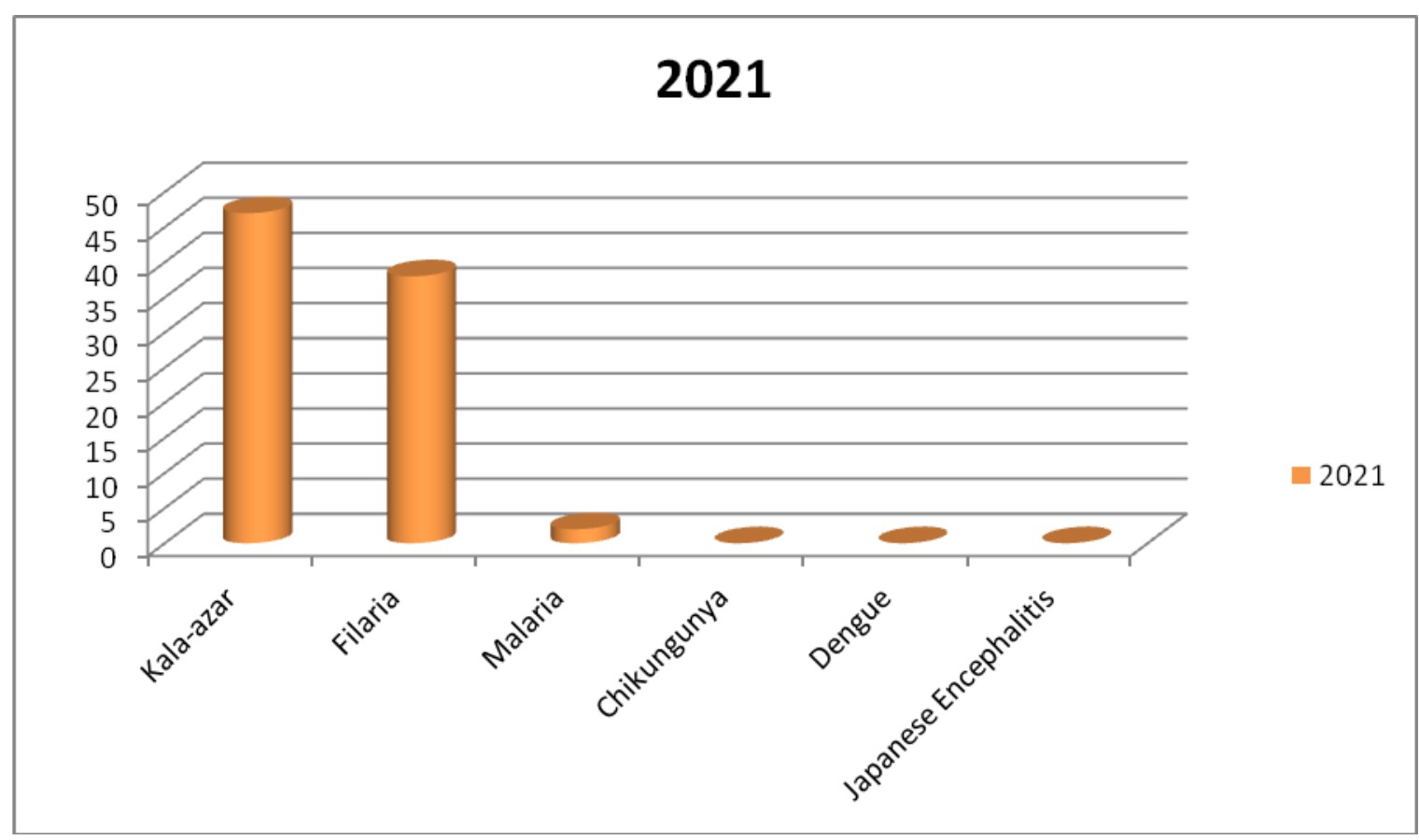

Fig-1 Vector borne diseases from January 2021 to June 2021

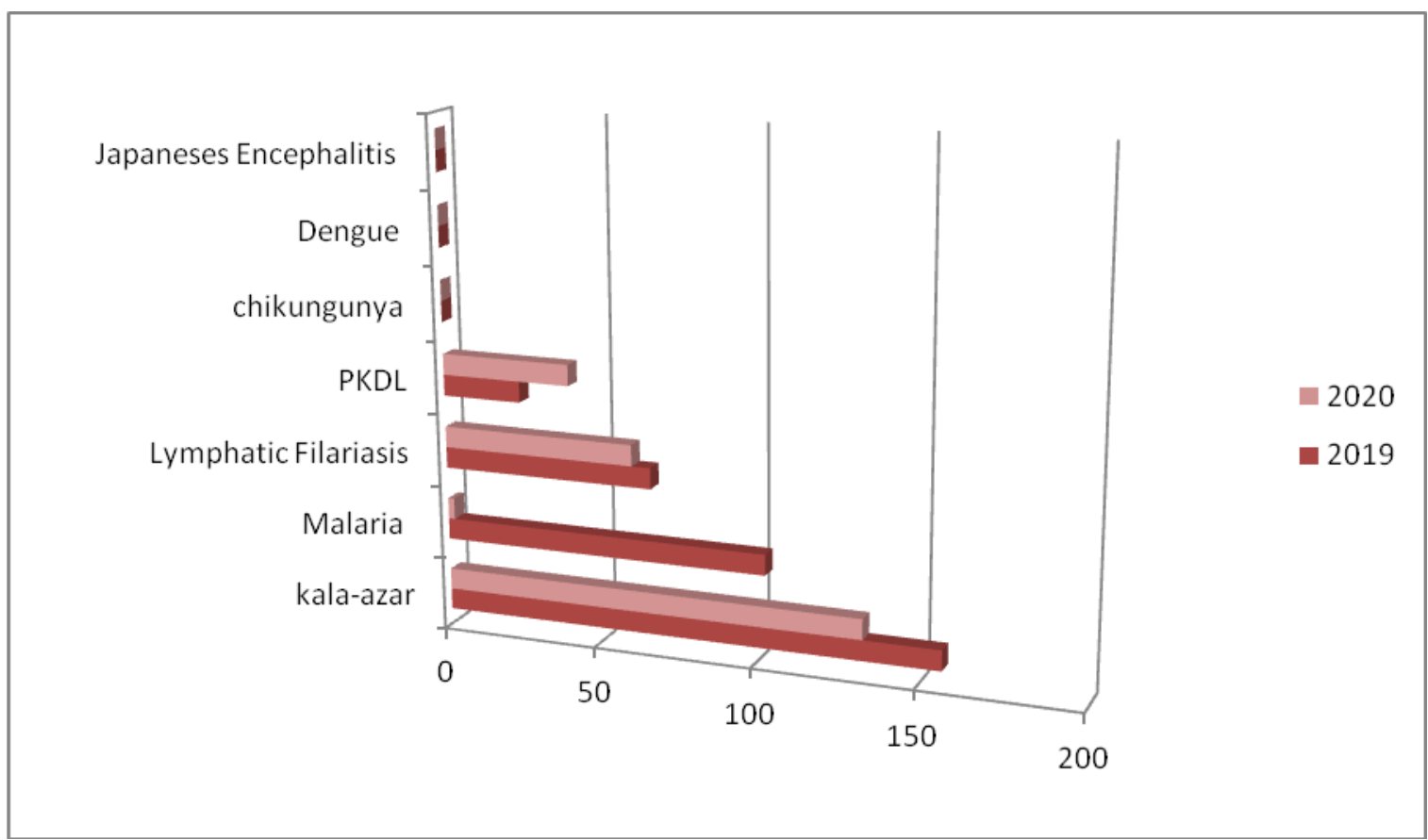

Fig-2 Trends of Vector-borne disease in 2019 and 2020 
Vidushi Topno et.al. Impact on vector-borne diseases in COVID-19 pandemic: evidence from a district in Jharkhand, India.

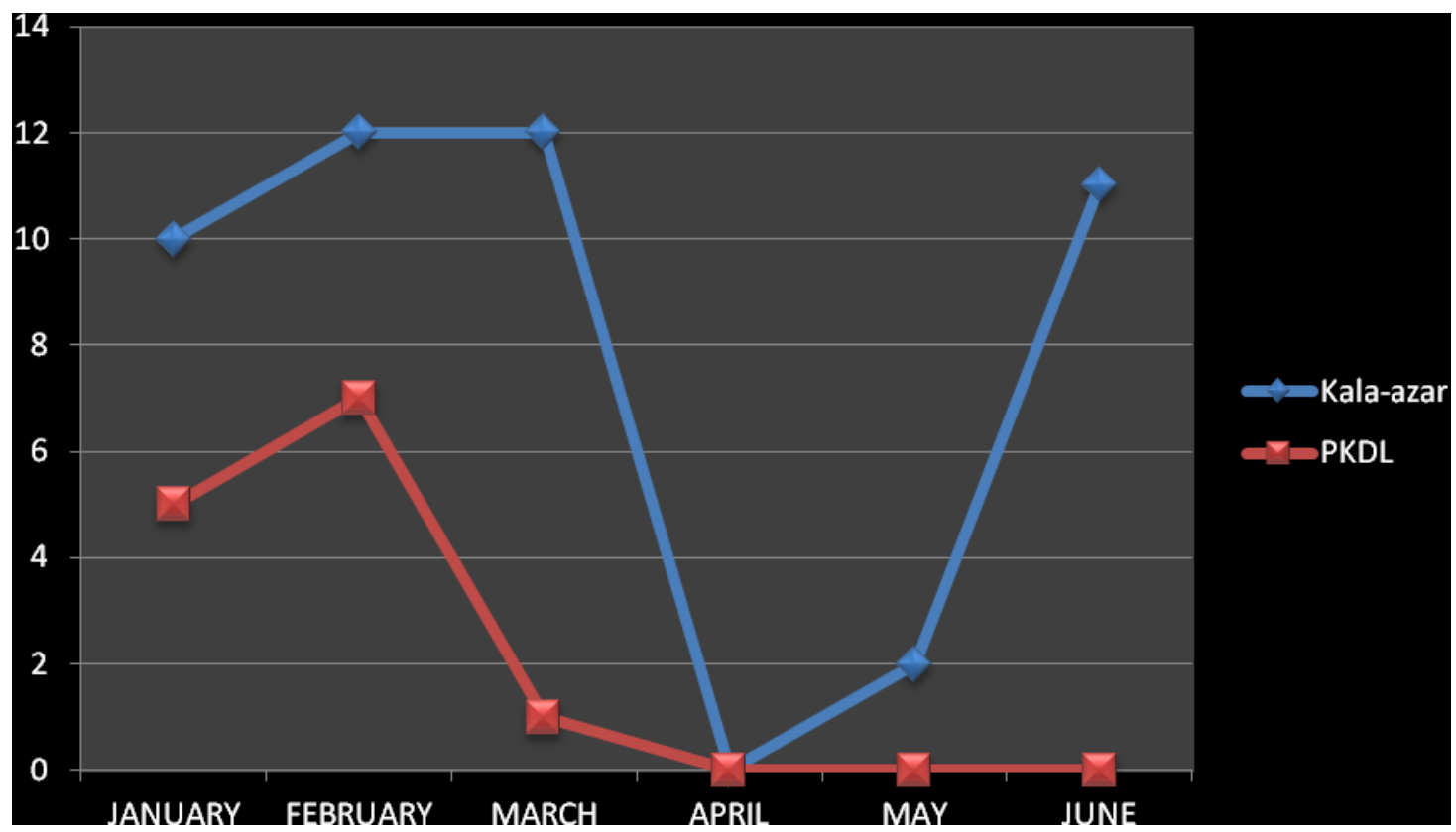

Fig-3 Kala-azar and PKDL during January 2021 to June 2021

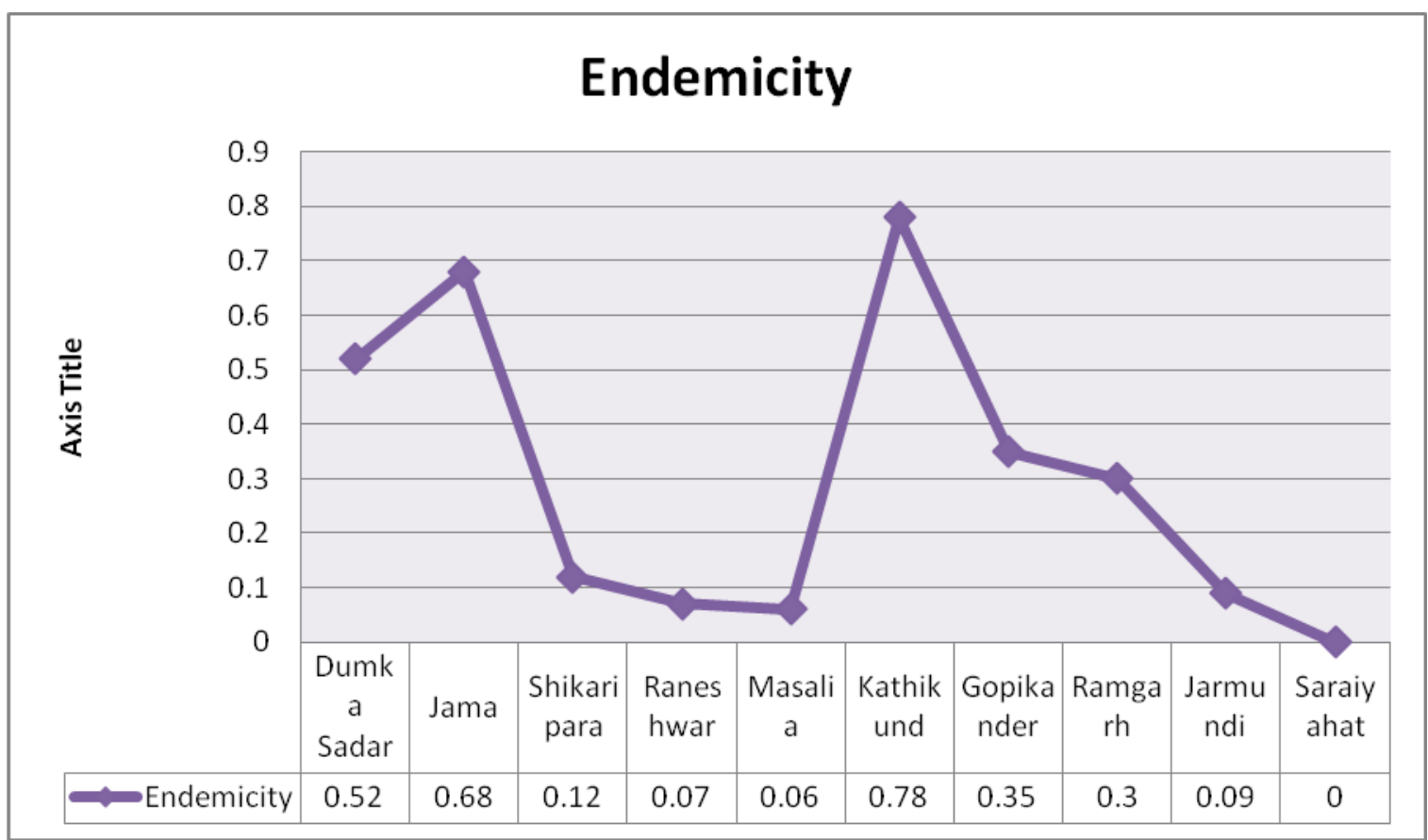

Fig-4 Endemicity of Kala-azar during January 2021 to June 2021 in 10 Blocks of Dumka District

\section{DISCUSSION}

A decrease in number of cases for nearly all vector borne diseases was recorded. There may multifactorial reasons behind changes in the number of cases recorded. With our routine surveillance data it can't be fully explained. We were unable to take the account of health and health seeking behaviour, which influence to a large extent for subsequent diagnosis and reporting. Drastic reduction in vector borne diseases especially malaria has to taken under vigilant study. To know the role of under diagnosis for decrease in notification, further investigation is needed. Another reason can be that people do get afraid to go to health care facilities due to fear of getting COVID-19 infection. There was presence of male cases predominance in all vector-borne diseases. The reduction of Kala-azar cases 
Vidushi Topno et.al. Impact on vector-borne diseases in COVID-19 pandemic: evidence from a district in Jharkhand, India.

15.3\%, Lymphatic Filariasis $8.9 \%$, Malaria 98.1\%. But rise PKDL cases (64\%) was seen from 2019 to 2020.

Reason for decline in the number of people affected with vector -borne disease can also be intake of immunity boosters, good hygiene practices and prophylaxis. Earlier less attention was given by people community information through leaflets, television, radio etc. During lockdown people started paying attention to that information. This information caused increase in awareness among people and started cleaning homes and surroundings. The COVID-19 pandemic magnify socioeconomic inequalities in health, thus putting lower socio -economic status at increased risk for COVID -19, as well as other communicable and non-communicable public health menace. ${ }^{16,17}$ All infectious diseases public risk perception and its related prevention measures, are robust and closely observed to allow prompt adaptation for long-term confidence in public health authorities. ${ }^{18}$

\section{CONCLUSION}

Though there is dominance of COVID-19 surveillance, other vector borne disease must not be overlooked. Vectorborne diseases transmission pattern changes, health care utilisation behaviour of patients, any under diagnosis due to various reasons should be monitored. Accessibility and safety of all clinical and preventive health services should be highlighted in public health communication and urge people to pursue healthcare whenever needed. Healthcare services should remain operational and known to be approachable and safe for public.

Acknowledgement: None

Conflict of Interest: None

Source of Funding: None

Ethical Approval: Approved

\section{REFERENCES}

1. Sintema, E. J. (2020, April 7). Effect of COVID-19 on the performance of grade 12 students: Implications for STEM education. EURASIA Journal of Mathematics, Science and Technology Education, 16(7). https://doi.org /10.29333/ejmste/7893

2. World Health Organization SMALL BITE:BIG THREAT, Fact sheets on vector borne diseases in India 2014 https://www.who.int/docs/defaultsource/searo/india/health-topic-pdf/vbdfact-sheets.pdf?sfvrsn=c1908b04_2

3. Ranjan A, Sur D, Singh VP, Siddigue NA, Manna B, Lal CS, Sinha PK, Kishore K, Bhattacharya SK, 2005. Risk factors for Indian kala-azar. Am J Trop Med Hyg 73: 74-78.

4. Kumar V, Mandal R, Das S, Kesari S, Dinesh DS, Pandey K, et al. (2020) Kalaazar elimination in a highly-endemic district of Bihar, India: A success story. PLoS Negl Trop Dis 14(5):e0008254. https://doi.org/10.1371/journal.pntd.000825 4

5. World malaria report 2011. Geneva: World Health Organization; [accessed on March 11, 2014]. WHO. Available from: http://www.who.int/malaria/world_malaria _report_2011/9789241564403_eng.pdf .

6. Das MK, Prajapati BK, Tiendrebeogo RW, et al. Malaria epidemiology in an area of stable transmission in tribal population of Jharkhand, India. Malar J. 2017;16(1):181. Published 2017 May 2. doi:10.1186/s12936017-1833-9

7. WHO urges countries to ensure the continuity of malaria services in the context of the COVID-19 pandemic. 2020 March 25 [Cited 2020 March 31]. In: World Health Organization. Press release [Internet]. Geneva, Switzerland: WHO. [About 2 screens.] https://www.who.int/newsroom/detail/25-03-2020- who-urgescountries-to-ensure-the-continuity-ofmalaria-services-in-the-context-of-thecovid-19- pandemic.

8. Susanta Kumar Ghosh, Pradeep Kumar Srivastava A New Outlook in Lymphatic Filariasis Elimination in India DOI: http://dx.doi.org/10.5772/intechopen.92454

9. WHO (2017) Global programme to eliminate lymphatic filariasis: Progress report 2016. WHO Weekly Epidemiological Record 40: 589-608. 
Vidushi Topno et.al. Impact on vector-borne diseases in COVID-19 pandemic: evidence from a district in Jharkhand, India.

10. 1. WHO. Lymphatic Filariasis. Geneva: WHO; 2020. Available from: https:// www.who.int/news-room/factsheets/detail/lymphatic-filariasis.

11. Seelig F, Bezerra H, Cameron M, Hii J, Hiscox A, Irish S, et al. (2020) The COVID19 pandemic should not derail global vector control efforts. PLoS Negl Trop Dis 14(8): e0008606.

https://doi.org/10.1371/journal.pntd.000860 6

12. Andrews et al: First COVID-19 Case In India. Indian J Med Res 151, May 2020, pp 490-492 DOI: 10.4103/ijmr.IJMR_2131_20

13. COVID -19 pandemic in India, from Wikipedia https://en.wikipedia.org/wiki/COVID19_pandemic_in_India

14. Rodriguez-Morales AJ, Gallego V, Escalera-Antezana JP, Méndez CA, Zambrano LI, Franco-Paredes C, et al. COVID-19 in Latin America: The implications of the first confirmed case in Brazil. Travel Med Infect Dis. May-Jun 2020; 35:101613.

15. https://doi.org/10.1016/j.tmaid.2020.101613 PMID: 32126292;. 5. Griffin O. 'Dengue kills too'-Latin America faces two epidemics at once. Reuters World News. 2020 May 12 [Cited 2020 July 3]. https://www.reuters.com/article/us-healthcoronavirus-latam-dengue-

featuidUSKBN22O1W2

16. Wachtler B., Michalski N., Nowossadeck E., Diercke M., Wahrendorf M., SantosH€ovener C., et al. Socioeconomic inequalities and COVID-19 _ a review of the current international literature. Journal of Health Monitoring, 2020(S7):3_17.

17. Wachtler B., Michalski N., Nowossadeck E., Diercke M., Wahrendorf M., SantosH€ovener C., et al. Socioeconomic inequalities in the risk of SARS-CoV-2 infection_ First results from an analysis of surveillance data from Germany. Journal of Health Monitoring, 2020(S7):18_29.

18. Betsch C, Wieler L, Bosnjak M, Ramharter M, Stollorz V, Omer S, et al. Germany COVID-19 Snapshot MOnitoring (COSMO Germany): monitoring knowledge, risk perceptions, preventive behaviours, and public trust in the current coronavirus outbreak in Germany. Psych Archiv 2020.

How to cite this article: Vidushi Topno, Vikas Oraon. Impact on vector-borne diseases in COVID-19 pandemic: evidence from a district in Jharkhand, India. International Journal of Research and Review. 2021; 8(12): 424-430. DOI: https://doi.org/10.52403/ijrr.20211252 